\title{
Initial Activation and Operation of the Power Conditioning System for the National Ignition Facility
}

M.A. Newton, R.E. Kamm, E.S. Fulkerson, S.D. Hulsey, N. Lao, G.L. Parrish, D.L. Pendleton, D.E. Petersen, M. Polk, J.M. Tuck, G.T. Ullery of Lawrence Livermore National Laboratory, Livermore, CA 94550, USA and W.B. Moore of Sandia National Laboratory, Albuquerque, NM 8185 USA

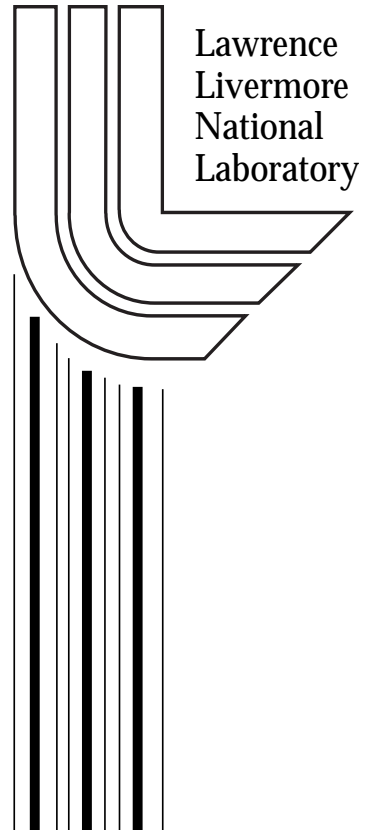

This article was submitted to International Pulsed Power Conference 2003, Dallas, TX June 15-18, 2003

\section{August 20, 2003}




\section{DISCLAIMER}

This document was prepared as an account of work sponsored by an agency of the United States Government. Neither the United States Government nor the University of California nor any of their employees, makes any warranty, express or implied, or assumes any legal liability or responsibility for the accuracy, completeness, or usefulness of any information, apparatus, product, or process disclosed, or represents that its use would not infringe privately owned rights. Reference herein to any specific commercial product, process, or service by trade name, trademark, manufacturer, or otherwise, does not necessarily constitute or imply its endorsement, recommendation, or favoring by the United States Government or the University of California. The views and opinions of authors expressed herein do not necessarily state or reflect those of the United States Government or the University of California, and shall not be used for advertising or product endorsement purposes.

This is a preprint of a paper intended for publication in a journal or proceedings. Since changes may be made before publication, this preprint is made available with the understanding that it will not be cited or reproduced without the permission of the author.

This report has been reproduced directly from the best available copy.

Available electronically at http://www.doc.gov/bridge

Available for a processing fee to U.S. Department of Energy

And its contractors in paper from U.S. Department of Energy

Office of Scientific and Technical Information

P.O. Box 62

Oak Ridge, TN 37831-0062

Telephone: (865) 576-8401

Facsimile: (865) 576-5728

E-mail: reports@adonis.osti.gov

Available for the sale to the public from U.S. Department of Commerce

National Technical Information Service

5285 Port Royal Road

Springfield, VA 22161

Telephone: (800) 553-6847

Facsimile: (703) 605-6900

E-mail: orders@ntis.fedworld.gov

Online ordering: http://www.ntis.gov/ordering.htm

OR

Lawrence Livermore National Laboratory

Technical Information Department's Digital Library

http://www.llnl.gov/tid/Library.html 


\title{
INITIAL ACTIVATION AND OPERATION OF THE POWER CONDITIONING SYSTEM FOR THE NATIONAL IGNITION FACILITY*
}

\author{
M.A. Newton, R.E. Kamm, E.S. Fulkerson, S.D. Hulsey, N. Lao, G.L. Parrish, D. L. \\ Pendleton, D. E. Petersen, M. Polk, J.M. Tuck, G.T. Ullery \\ Lawrence Livermore National Laboratory, 7000 East Avenue \\ Livermore, CA 94550 USA \\ W.B. Moore \\ Sandia National Laboratory, Albuquerque, NM 87185 USA
}

\begin{abstract}
The National Ignition Facility (NIF) Power Conditioning System (PCS) is a modular capacitive energy storage system that will be capable of storing nearly $400 \mathrm{MJ}$ of electrical energy and delivering that energy to the nearly 8000 flashlamps in the NIF laser. The first sixteen modules of the power conditioning system have been built, tested and installed. Activation of the first nine power conditioning modules has been completed and commissioning of the first "bundle" of laser beamlines has begun. This paper will provide an overview of the power conditioning system design and describe the status and results of initial testing and activation of the first "bundle" of power conditioning modules.
\end{abstract}

\section{INTRODUCTION}

The National Ignition Facility (NIF) is a laser-driven inertial-fusion facility being built by the Lawrence Livermore National Laboratory for the United States Department of Energy. The NIF laser, shown in Figure 1, is a 192-beam, flashlamp-driven neodymium-glass laser that will produce $1.8 \mathrm{MJ}$ of light on target. Each of the 192 beams of the NIF laser is amplified in two multi-pass laser amplifiers, the Master Amplifier and the Power Amplifier. The Master Amplifier and the Power Amplifier will house the 7680 flashlamps that are driven by a modular power conditioning system that was designed and developed by Sandia National Laboratory (SNL) in Albuquerque [1],[2] in collaboration with Lawrence Livermore National Laboratory (LLNL).

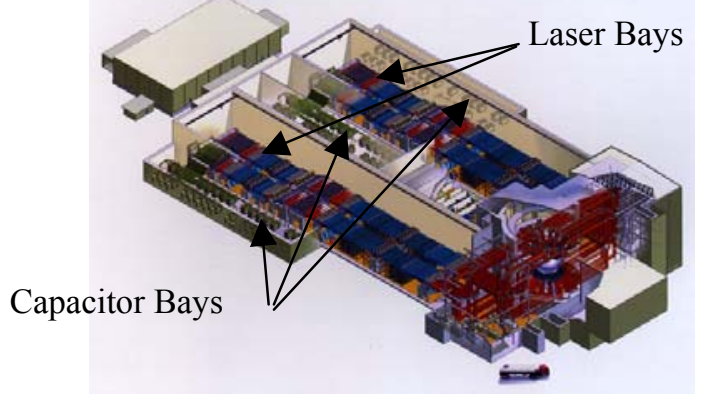

Figure 1. The National Ignition Facility
The NIF Power Conditioning System (PCS) resides in four Capacitor Bays, supplying energy to the Master and Power Amplifiers which reside in the two adjacent laser bays. Each capacitor bay will initially house 48 individual power conditioning modules, shown in Figure 2 , with space reserved for expansion to 54 modules.

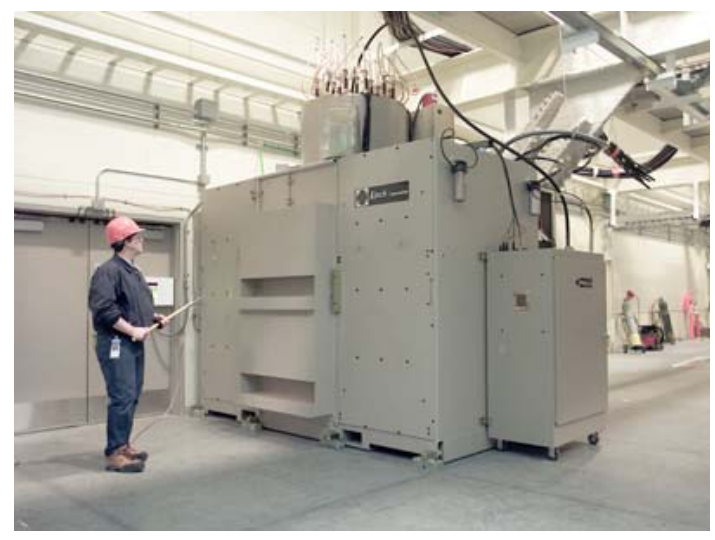

Figure 2. PCS module installed in NIF capacitor bay.

Completion of the NIF laser is planned for 2008. However, the first four of 192 laser beams were activated and commissioned in 2002 to demonstrate and test the system designs before continuing with procurement and construction of the remaining laser equipment. This early activation of the first four beams of the NIF laser is referred to as "NIF Early Light" or NEL.

In support of the NEL campaign, nine PCS Modules, driving a single bundle of eight laser beams were commercially built, installed and tested. Commissioning of the first nine PCS modules has been completed and routine operation of the laser is proceeding.

\section{MODULE DESCRIPTION}

The power conditioning modules were designed to be a cost effective, efficient, reliable and transportable energy storage system for NIF. Each module is a simple RLC 
discharge circuit that is independently controlled and operated. The output requirements of the modules are based on empirically-determined optimum drive requirements for the NIF laser. Each module must deliver a set of two pulses to the NIF flashlamps. The purpose of the first lower energy 100 microsecond pulse is to preionize the lamps prior to delivering the main pulse as shown in Figure 3. Approximately $500 \mathrm{~J} / \mathrm{lamp}$ is delivered during the pre-ionization pulse. The main discharge pulse, which provides the pump energy for the

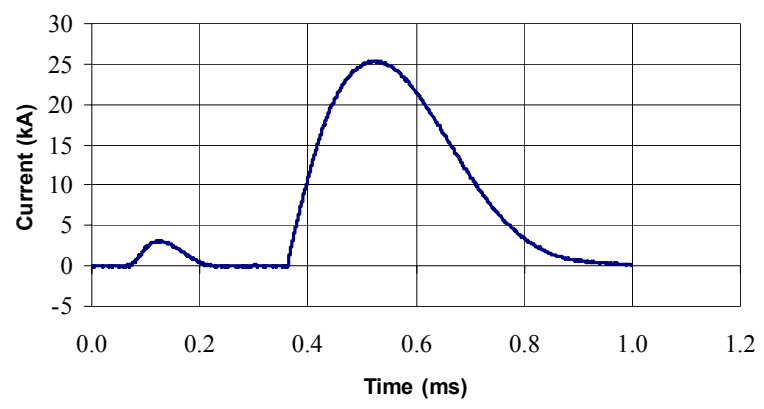

Figure 3. Typical output pulse of NIF PCS module showing initial pre-ionization pulse and main energy discharge.

laser glass occurs approximately $300 \mu$ s later and delivers a minimum of $34 \mathrm{~kJ}$ to each lamp. A simplified schematic of the module is shown in Figure 4.

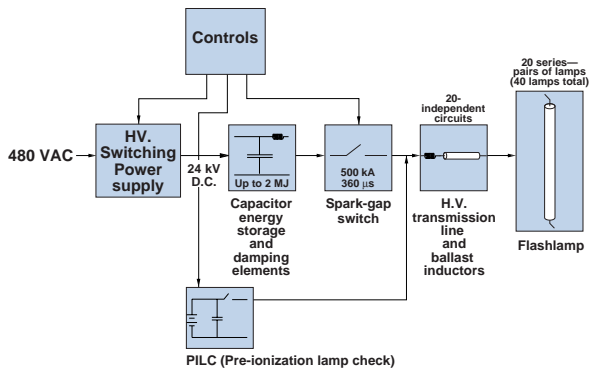

Figure 4. Schematic of NIF Power Conditioning Module.

A single power conditioning module can store over 2 MJ of electrical energy and is independently charged to a maximum of $24 \mathrm{kV}$ in $60-80$ seconds. The energy is stored in 20-24, $84 \mathrm{~kJ}$ capacitors that are isolated from each other through resistive inductors called damping elements. The stored energy is discharged through a single spark-gap switch, ST-300, into twenty coaxial cables that carry the energy to the NIF flashlamps. Ballast inductors force the energy to divide equally among the 20 parallel output circuits. Each output circuit drives a series pair of 1.8 meter flashlamps in the Master Amplifier and the Power Amplifier.

\section{CABLE PLANT DESCRIPTION}

Commercial Underground Residential Distribution (URD) high voltage cable is used to deliver the energy from the PCS modules to the NIF laser amplifiers. Onequarter (approximately 25 miles) of the total high voltage cable required for NIF has been installed in capacitor bay 3. The cable is installed in grounded aluminum enclosures (shown in figure 5) that serve as ground return paths in the event of dielectric faults in the amplifier system. The enclosures were designed to maintain the potential of the amplifier structure below $500 \mathrm{~V}$ in the event of the most catastrophic fault.

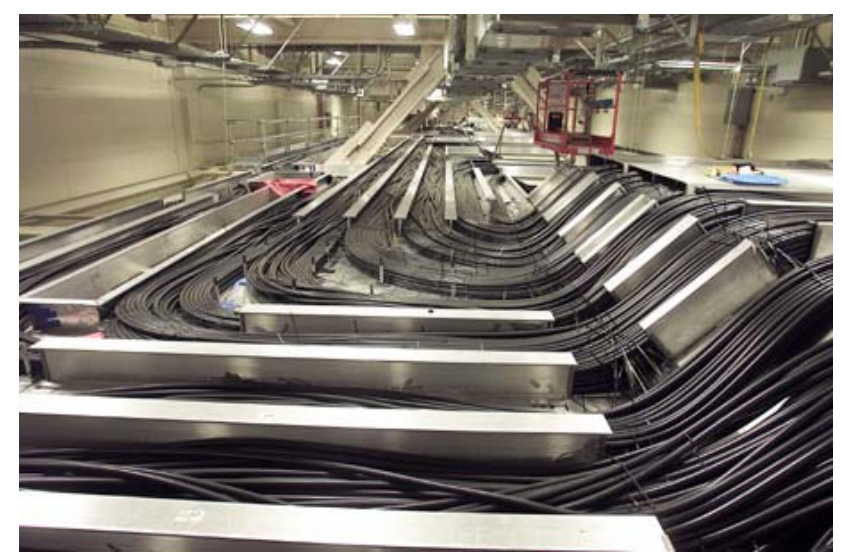

Figure 5. High Voltage Cable Plant in Capacitor Bay 3. Enclosures shown before covers were installed.

\section{CONTROLS DESCRIPTION}

The control system which operates the Power Conditioning System utilizes a three level hierarchical architecture. At the upper end, the supervisory and front end processors are part of the NIF Integrated Computer Control System (ICCS). Functionality provided by these layers include: Control Network Services; Embedded Processor Boot Server; Graphical User Interfaces (GUIs); Control Sequences including Automatic shutdown; alert messaging; Waveform Data Analysis and Archive; Databases for control parameters, calibration parameters, and data archive; Safety permissive; and Shot Timing. These functions and hardware are common to all PCS modules. At the lowest level are separate local controls housed in each PCS module control rack shown in Figure 5. The local controls consist of 480VAC power distribution, a gas pressure controller and an embedded controller. The local controls interface to ICCS through six fiber cables. These fibers provide ethernet communication, a high voltage permissive and three timing triggers (data acquisition, PILC and Main). The PCS module cannot be operated solely from the local controls; the ICCS or stand-alone supervisory controls are required. 
At the heart of the local controls is the embedded controller (EC). The EC utilizes a diskless Pentium-class single board computer running VX Works. Boot-up and execution of the control application is automatic upon power-up of the EC. Commercial I/O boards are used to provide the analog and digital I/O. Independent digital and analog modules provide electrical isolation of all control and monitor signals to/from the gas pressure controller, HV power supplies, dump switches and trigger generators. A custom-built data acquisition system (DAS) acquires current waveforms associated with the capacitor discharge (shot). It is comprised of 6ea four-channel digitizer boards and a control board. Each digitizer board has independent 12 bit ADCs that run at $5 \mathrm{Ms} / \mathrm{s}$ and store $8 \mathrm{k}$ samples. The control board interfaces to the EC through a standard parallel port. Transient protection boards are used to protect the DAS inputs. The EC, I/O interfaces, isolation modules, DAS and transient protection boards are mounted in an RFI enclosure to help shield them from the electrical noise resulting from the 2MJ discharge.

A Gas Pressure Controller (GPC) provides control of the air system for the Main and PILC spark gap switches. It also provides further isolation between the digital $\mathrm{I} / \mathrm{O}$ of the EC and the devices that are controlled with 120vac (trigger generators and dump switches).

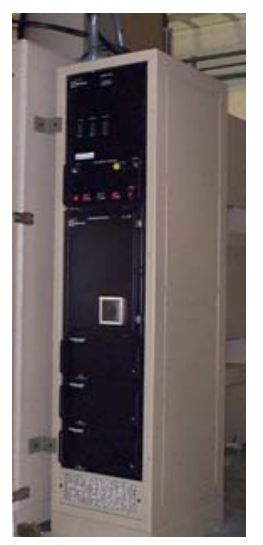

Figure 5. PCS Module Control Rack

\section{TEST DESCRIPTION}

The NIF module design has been thoroughly tested throughout its design and development [3] [4], however, multiple modules had never been operated as a system prior to the initial activation tests.

The NIF power conditioning system was activated in two phases after installation into the NIF facility. The first phase of the testing was primarily a re-test of the module after shipping from the subcontractor's facility. Although each module was thoroughly tested by the subcontractor at their facility, they were retested at LLNL after shipping and installation to verify that the PCS modules could be transported with no degradation in performance. The retest consisted of firing each module into a short circuit load for testing at full-rated current (but reduced charge voltage) to test all high current connections and then charging to full voltage to test the high voltage integrity of the system. Each of the nine modules for the NEL campaign were tested prior to connecting the cables to the laser amplifiers.

The output cables from the PCS modules to the Main and Power Amplifiers were connected after completion of the first phase of testing. The second phase of testing consisted of discharging each module individually into the main laser amplifiers, followed by multiple module testing. The number of modules operated together was gradually increased from two to the full nine modules.

In addition to the operational testing of the modules, tests were also conducted to validate the modeling of the PCS ground system [5]. This test was conducted by discharging the PILC circuit into the PCS ground system at the amplifier and measuring the potential of the amplifier during the discharge. The results of the ground system test were consistent with the design calculations.

\section{TEST RESULTS}

All of the power conditioning modules performed as expected. No issues were introduced due to transportation of the modules from the subcontractor's site. Each of the modules met or exceeded the system requirements shown in Table 1.

\begin{tabular}{|c|c|}
\hline $\begin{array}{l}\text { Average Gain Coefficient } \\
(\mathrm{AGC}) *\end{array}$ & $\geq 5.0 \% / \mathrm{cm}$ \\
\hline Shot-to-shot variability & $\leq \pm 1.0 \%$ in energy \\
\hline Lamp-to-lamp variability & $\leq \pm 3.0 \%$ in energy \\
\hline $\begin{array}{l}\text { Delivered energy } \\
\text { (kJ/lamp) }\end{array}$ & $\geq 34$ \\
\hline Module Jitter $(\mu \mathrm{s})$ & $\leq 2$ \\
\hline
\end{tabular}

Table 1. Primary Power Conditioning System Performance Requirements

After the completion of the two phases of PCS activation testing, routine operation began. To date, approximately 90 system shots (shots involving a minimum of 5 modules) have been successfully conducted in addition to the 1500 module shots that were conducted during the two phases of the PCS activation testing. No major design changes in the PCS modules are needed or anticipated based on operational experience of NEL. 


\section{REFERENCES}

[1] M.A. Newton, D.W. Larson, J.M. Wilson, H.C. Harjes, M.E. Savage, R.L. Anderson, "Power Conditioning Development for the National Ignition Facility," Proceedings of SPIE Second International Conference on Solid State Lasers for Application to Inertial Confinement Fusion, Paris, France, 1996.

[2] M.A. Newton, E. S. Fulkerson, S. D. Hulsey, R. E. Kamm, D. L. Pendleton, D. E. Petersen, C. R. Smith, G.T. Ullery, P. F. McKay, W. B. Moore, D. A. Muirhead, "Overview and Status of the Power Conditioning System for the National Ignition Facility," Proceedings of Pulsed Power Plasma Science 2001 Conference, Las Vegas, Nevada, 2001, p. 405.

[3] D.L. Smith, J. Hammon, J.M. Wilson, H.C. Harjes, W. B. Moore, "FANTM: First Article NIF Test Module", IEEE Transactions on Plasma Science, Special Issue on Pulsed Power Science and Technology volume 28, Number 5, pages 1316-1323 (October 2000)

[4] E.S. Fulkerson, M.A. Newton, S. Hulsey, J. Hammon, W.B. Moore, "NIF Power Conditioning System Testing at LLNL," Proceedings of Pulsed Power Plasma Science 2001 Conference, Las Vegas, Nevada, 2001, p. 1524.

[5] J. Hammon, E.S. Fulkerson, W. Gagnon, R. Anderson, "Safety Grounding Approach for the National Ignition Facility Power Conditioning System," Proceedings of Pulsed Power Plasma Science 2001 Conference, Las Vegas, Nevada, 2001, p. 1547.

This work was performed under the auspices of the U.S. Department of Energy by University of California, Lawrence Livermore National Laboratory under contract No. W-7405-Eng-48. 